
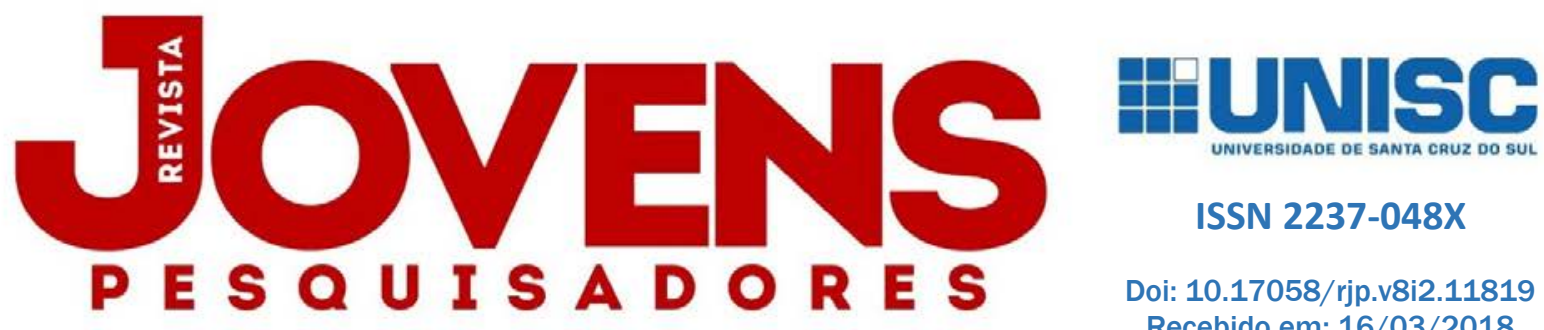

ISSN 2237-048X

Doi: $10.17058 /$ rjp.v8i2.11819

Recebido em: 16/03/2018

Aceito em: 15/06/2018

\title{
O PROCESSO DE INTERVENÇÃO EM PROJETOS DE EXTENSÃO E A APROPRIAÇÃO DE TECNOLOGIAS DE GESTÃO PELA AGRICULTURA FAMILIAR NO VALE DO CAÍ / RS
}

\author{
RITT, D.1; BARCELOS, L.1; DEPONTI, C. M.3; KIST, R. B. B.2; AREND, S. C. ${ }^{3}$;
}

PALAVRAS CHAVE: Tecnologias de Informação e Comunicação. Desenvolvimento regional. Extensão Universitária.

\section{RESUMO}

0 presente artigo refere-se ao projeto de pesquisa e de extensão denominado "O uso e a apropriação de TICs pela agricultura familiar no Vale do Caí - RS", financiado pelo edital do MCTI/CNPq. 0 projeto conta com a parceria da EMATER/ASCAR-RS, do Sindicato dos Trabalhadores Rurais do município de Montenegro-RS, das escolas rurais situadas no Vale do Caí e dos alunos dos cursos de graduação em Ciências Contábeis e Administração de Empresas do Campus de Montenegro/UNISC. Para realização das atividades de extensão vinculadas ao projeto acima referido, no ano de 2017 foi criado o Núcleo de Extensão Tecnológica e Gestão Rural para Agricultura Familiar no Vale do Caí com o objetivo principal de receber as demandas de agricultores familiares do Vale do Caí/RS relacionadas à gestão rural. Verifica-se que o processo de intervenção realizado junto aos agricultores familiares possibilita a compreensão da necessidade de se considerar as particularidades concretas de todos os agricultores, pois eles não podem ser analisados sob um mesmo patamar à medida que se identificam diferenças no que tange aos sistemas de sentido, de significados e, especialmente, com relação às suas condições objetivas de vida. Quanto à apropriação das TIC verificou-se que as formas de controle e de gerenciamento disponíveis no mercado não captam a diversidade e a particularidade da gestão rural das propriedades. Concluiu-se que há necessidade de construção de alternativas que deem conta de tal situação, pois frente ao mercado em um sistema capitalista processos mais adequados à realidade tornam-se imprescindíveis.

\section{THE PROCESS OF INTERVENTION IN EXTENSION PROJECTS AND THE APPROPRIATION OF MANAGEMENT TECHNOLOGIES BY FAMILY FARMING IN THE CAÍ VALLEY / RS}

KEYWORDS: Information and Communication Technologies. Regional development. University Extension.

\begin{abstract}
This article refers to the research and extension project called "The use and appropriation of ICTs by family farms in the Vale do Caí-RS", financed by the edict of MCTI / CNPq. The project counts on the partnership of EMATER / ASCAR-RS, the Union of Rural Workers of the municipality of Montenegro-RS, the rural schools located in Vale do Caí and the students of the undergraduate courses in Accounting and Business Administration of the Campus of Montenegro/UNISC. In order to carry out the extension activities related to the above mentioned project, in 2017 the Technological Extension and Rural Management Center for Family Agriculture was created in Vale do Caí with the main objective of receiving the demands of family farmers of the Vale do Caí/RS related to rural management. It can be seen that the intervention process carried out with family farmers makes it possible to understand the need to take into account the specific characteristics of all farmers, since they can not be analyzed under one single level insofar as differences in refers to the systems of meaning, meanings and, especially, in relation to their objective conditions of life. Regarding the appropriation of ICT, it was verified that the forms of control and management available in the market do not capture the diversity and the particularity of the rural management of the properties. It was concluded that there is a need to construct alternatives that account for such a situation, because processes facing the market in a capitalist system more appropriate to reality become essential.
\end{abstract}

\footnotetext{
${ }^{1}$ Acadêmicos do curso de Administração na Universidade de Santa Cruz do Sul - Campus Montenegro.

2 Docente do Departamento de Ciências Humanas na Universidade de Santa Cruz do Sul.

${ }^{3}$ Docentes do Departamento de Ciências Econômicas na Universidade de Santa Cruz do Sul.
} 


\section{INTRODUÇÃO}

Uma experiência de extensão tecnológica representa uma forma de intervenção realizada por determinados atores em uma realidade concreta. No caso do projeto ora analisado esse processo ocorre através da intervenção de uma equipe de alunos, de professores, de pesquisadores e de demais atores da sociedade em um ambiente de agricultura familiar no Vale do Caí.

O surgimento das novas Tecnologias da Informação e Comunicação (TIC) ocorreu entre os anos de 1960 e 1970. No que se refere especificamente à agricultura familiar identifica-se a existência de importantes avanços decorrentes da introdução e da utilização das TIC, especialmente a qualificação dos processos de gestão das propriedades rurais. Entretanto, há que se reconhecer, também, a existência de alguns desafios (MACHADO, DEPONTI e KIST, 2017).

No presente artigo compreende-se TIC como as tecnologias de informação e de comunicação, tais como a televisão, o rádio, o telefone fixo, o telefone celular, o computador de mesa, o notebook e o tablet. Além disso, considerou-se o acesso à internet e a utilização de livros, de jornais, de revistas.

Segundo Pedroso (1999), a tecnologia pode ser classificada em cinco categorias: a) tecnologia de processo; b) tecnologia de materiais; c) tecnologia de produtos e serviços; d) tecnologia da informação; e, e) tecnologia de gestão. Neste artigo as tecnologias analisadas serão as de informação e de gestão que contribuem para o desenvolvimento das propriedades rurais.

Além dos conceitos acima se descreve a compreensão e a diferenciação que a pesquisa utiliza entre uso e apropriação de TIC, ou seja, os usos das TIC se referem à utilização dessas tecnologias, tais como o celular, o computador, a Internet, na vida cotidiana possibilitando a comunicação e a troca de informações. Já as apropriações constituem-se em maior domínio dessas tecnologias, ou seja, referem-se ao processo de sua utilização para além da troca de informação, para a qualificação dos processos de gestão, de controle da propriedade e para ampliação da interação com os demais agricultores e organizações vinculadas ao rural. Dessa forma, quanto maior a apropriação das TICs, maior a inclusão digital do meio rural (FELIPPI; DEPONTI; DORNELES, 2015).

Ainda merece esclarecimento a compreensão do conceito de gestão rural, que se baseia em Pelegrini e Gazola (2008, p. 155), podendo ser definida:

como o processo em que o agricultor administra da melhor forma possível o seu empreendimento combinando, para isso, os recursos disponiveis como a força de trabalho familiar, os recursos econômicos, os conhecimentos técnico-produtivos, o capital social, os seus recursos naturais, etc para obter os melhores resultados e desenvolver de forma sustentável a sua unidade de produção e de processamento de alimentos.

No caso que será analisado pode-se definir que a gestão rural envolve não somente os aspectos vinculados ao controle contábil e gerencial, mas à propriedade como um todo, relacionando aspectos econômicos, financeiros, administrativos, ambientais, sociais que qualificam a tomada de decisão. Dessa forma, a gestão contábil e gerencial engloba ao controle de despesas e de receitas a partir de fluxo de caixa, informações mais detalhadas sobre renda bruta, renda líquida, índices de eficiência econômica, custos de produção.

0 artigo está dividido em quatro seções, além da introdução e das considerações finais. Na primeira seção tratase brevemente da revisão de literatura sobre TIC e agricultura familiar e, na segunda, apresenta-se a região de estudo da pesquisa. Na terceira seção discute-se o perfil, o uso e a apropriação das TIC pela agricultura familiar e na última apresenta-se a discussão sobre o processo de gestão rural realizado pelos agricultores familiares. 


\section{TIC E A AGRICULTURA FAMILIAR}

Compreende-se por Tecnologia de Informação e Comunicação (TIC) um conjunto de recursos tecnológicos que são utilizados de forma integrada e com base em um objetivo comum (PACIEVITCH, 2014). Nesse sentido, as TIC se referem às tecnologias de informação e de comunicação que medeiam as relações de comunicação estabelecidas entre as pessoas, processo que ocorre através da utilização de equipamentos como a televisão, o rádio, os telefones (fixos e celulares), os computadores (portáteis, de mesa e tablet), as antenas parabólicas e de recursos tecnológicos como a internet, a TV por assinatura, entre outros (CETIC, 2017; FELIPPI, DEPONTI, DORNELES, 2017).

A utilização das TIC ocorre das mais variadas formas, seja na indústria (processo de automação), na publicidade (gerenciamento), no setor de investimentos (informação simultânea), bem como na área da educação (na educação a distância e no processo de ensino aprendizagem) (LEADER, 2000), possibilitando a racionalização de custos e a obtenção de níveis elevados de desempenho entre as organizações empresariais.

Constata-se que a inclusão de tecnologias não ocorre de maneira universal na vida das pessoas, pois esse processo é multidimensional, sendo, portanto, determinado por fatores familiares, culturais, econômicos, sociais, educacionais, além de questões geográficas que podem facilitar ou impossibilitar o acesso. No que se refere especificamente ao meio rural, em que pese a identificação de fatores que podem dificultar o acesso e o uso das TIC, constata-se que elas podem contribuir para diversificar as atividades tradicionais das zonas rurais (agricultura, silvicultura, pesca, exploração mineira e produções derivadas) e para a expansão dos setores agro alimentar e de madeira, do artesanato e do turismo (CABRERA; SILVEIRA; SILVEIRA, 2010; LÜBECK, 2004; DEPONTI, 2017).

Nessa perspectiva, ressalta-se a importância de se compreender a diferença entre o uso e a apropriação das TIC, especialmente quando se analisa o meio rural. Autores como Felippi, Deponti e Dorneles (2017) e Arend, Deponti e Kist (2017) ressaltam que o uso está relacionado com todo o processo de utilização dessas tecnologias, tais como o celular, o computador, a internet na vida cotidiana para comunicação e troca de informações. A apropriação, por sua vez, relaciona-se com a possibilidade de haver maior domínio dessas tecnologias, o que pressupõe sua utilização para além da troca de informação, incluindo também a qualificação dos processos de gestão, o controle da propriedade e a ampliação da interação com os demais agricultores e organizações vinculadas ao rural.

Identifica-se que existe uma dissonância entre o uso e a apropriação das TIC em função de que a apropriação em si consiste em um processo de caráter dinâmico e social, que ultrapassa a relação entre os equipamentos e os conteúdos. Nesse sentido, a apropriação das TIC pelos agricultores consiste em um fator chave para que haja o processo de inclusão digital no meio rural (CETIC, 2016).

Compreende-se que a apropriação das TIC no meio rural pode contribuir para que haja muitos benefícios como a ampliação de horizontes e o atendimento de expectativas dos agricultores; a constituição de grupos e comercialização; a criação de políticas públicas; a constituição de cooperativas de produção e de crédito; a assistência técnica; a educação a distância, entre outros fatores (CETIC, 2016; BALBONI, 2007; BATALHA; BUAINAIN; SOUZA FILHO, 2005; ECKHARDT; LEMOS, 2007; LÜBECK, 2004; WAISELFISZ, 2007). Entretanto, ainda se observam dificuldades enfrentadas pelos produtores rurais para administrarem suas propriedades agrícolas em decorrência das mudanças que afetaram o meio rural nas últimas décadas, tornando as atividades agrícolas em "negócios agrícolas", de caráter empresarial, processo que tem exigindo dos mesmos um investimento e uma profissionalização no processo de adesão às novas tecnologias (VIERO; SOUZA, 2008).

Além das dificuldades encontradas pelos próprios agricultores familiares no que se refere ao uso e à apropriação das TIC se identifica que entre os técnicos há um baixo nível de qualificação em tecnologias de gestão, associado ao fato de que se verifica uma carência de políticas públicas de estímulo ao setor que privilegiem aspectos de gestão (CETIC, 2016; DEPONTI, 2014; AREND, DEPONTI, KIST, 2017). Por outro lado, constata-se que é fundamental que os próprios agricultores se comprometam e adotem tanto os processos de aprendizagem, como os hábitos de registro e de acompanhamento das despesas e das receitas, visando à garantia da gestão de suas 
propriedades pela agricultura familiar, além de haver a infraestrutura e a capacitação necessárias para que sejam atendidas as condições objetivas de acesso dos agricultores às novas tecnologias (DEPONTI, 2014; MARION; SEGATTI, 2006; BARCELOS et al, 2015, DEPONTI et al, 2015).

\section{COMPREENDENDO O EMPÍRICO: O VALE DO CAÍ}

o COREDE Vale do Caí foi criado no ano de 1992 e integra a Região Funcional 1, delimitação proposta pelo "Estudo de Desenvolvimento Regional e Logística do RS - Rumos 2015". Este agrupamento dos COREDEs se constitui como uma escala mais agregada que permite um tratamento de temas em nível regional (GOVERNO DO ESTADO DO RIO GRANDE DO SUL, 2015).

Conforme pode ser observado através da Figura 1, o espaço regional do COREDE Vale do Caí é composto por um total de 19 municípios, são eles: Alto Feliz, Barão, Bom Princípio, Brochier, Capela de Santana, Feliz, Harmonia, Linha Nova, Maratá, Montenegro, Pareci Novo, Salvador do Sul, São José do Hortêncio, São José do Sul, São Pedro da Serra, São Sebastião do Caí, São Vendelino, Tuparandi e Vale Real.

Figura 1: Municípios da região do COREDE Vale do Caí

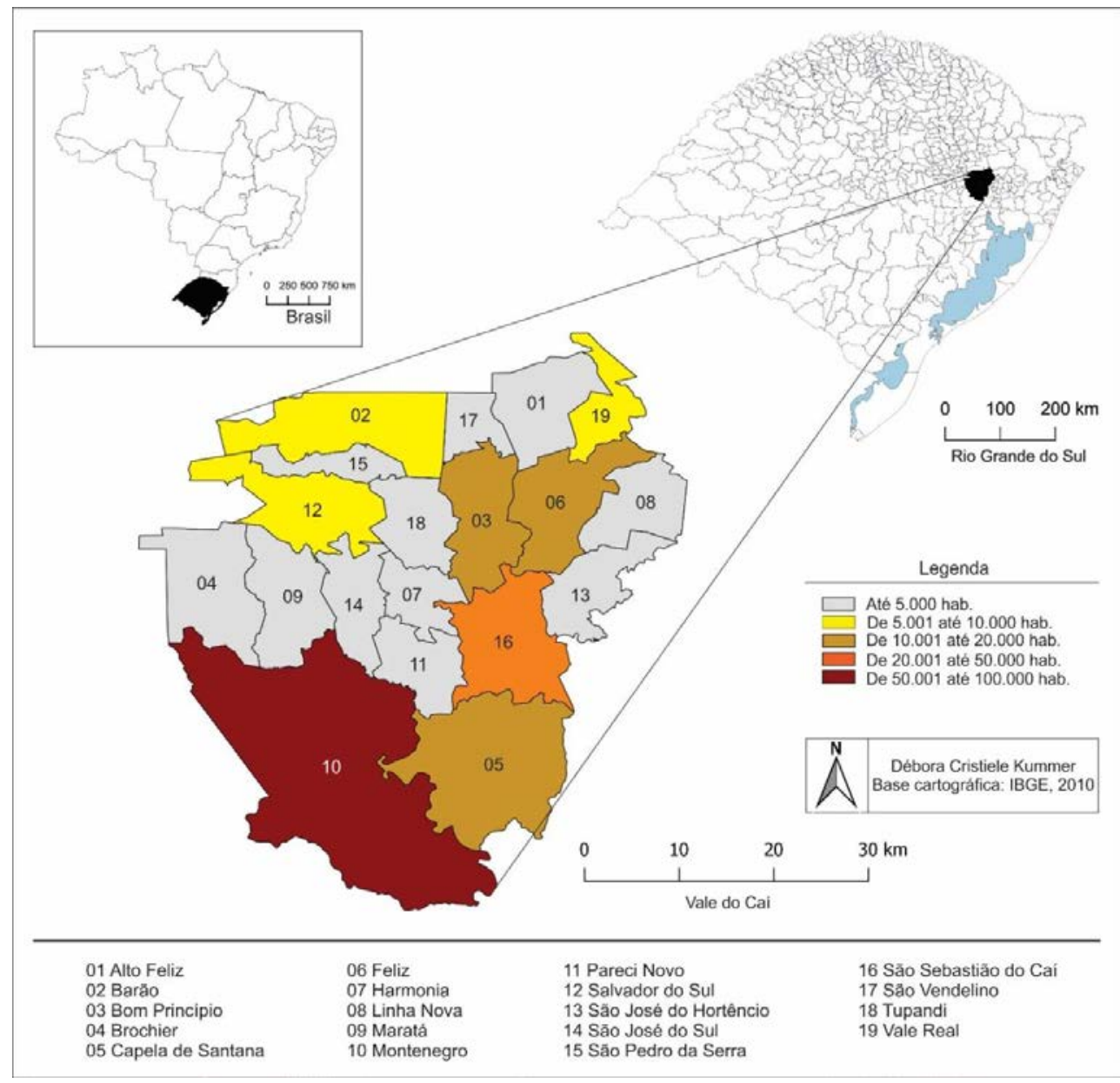

Fonte: Elaborado por Débora Cristiele Kummer (2017).

Observa-se que os municípios que apresentam maior população que vive no meio rural, em ordem decrescente, são Montenegro (5.786 habitantes); Capela de Santana (4.697 habitantes); São Sebastião do Caí (4.324 habitantes); Feliz (2.943 habitantes) e Harmonia (1.798 habitantes). Os municípios que apresentam a menor quantidade de pessoas no meio rural, em ordem crescente, são: Vale Real (552 habitantes); São Vendelino (591 habitantes); Tupandi (1.203 habitantes); Linha Nova (1.208 habitantes) e São José do Sul (1.362 habitantes). 
Os índices relativos à taxa de urbanização demonstram que os municípios que apresentam um percentual mais elevado de urbanização, em ordem decrescente, são: Montenegro (90,26\%); Vale Real (89,21\%); São Sebastião do Caí (80,28\%); Bom Princípio (78,02\%) e Feliz (76,18\%). Entre os municípios que apresentam menor taxa de urbanização, em ordem crescente, destacam-se: Linha Nova (25,61\%); Pareci Novo (27,94\%); Alto Feliz (27,97\%); Maratá (29,79\%) e São José do Sul (34,58\%).

Os municípios do COREDE Vale do Caí com maior PIB em 2014 eram, em ordem decrescente são Montenegro (R\$ 2.786.556,00); São Sebastião do Caí (R\$ 572.937,00); Bom Princípio (R\$ 433.040,00); Tupandi (R\$ $368.043,00)$ e Feliz (R\$ 351.011,00). Já os municípios que apresentaram menor PIB no período, em ordem crescente, destacam-se: Linha Nova (R\$ 41.932,00); São José do Sul (R\$ 52.855,00); São Vendelino (R\$ 53.199,00), São Pedro da Serra (R\$ 59.905,00) e Alto Feliz (R\$ 64.992,00).

No que se refere ao PIB per capita, observa-se que os municípios que apresentavam o maior valor no ano de 2014 eram, em ordem decrescente: Tupandi (R\$ 85.412,58); Montenegro (R\$ 44.328,85); Salvador do Sul (R\$ 36.971,41); Maratá (R\$36.626,63) e Barão (R\$33.769,90). Os municípios com menor PIB per capita, em ordem crescente, são: Capela de Santana (R\$ 14.915,19); Brochier (R\$ 15.420,12); São Pedro da Serra (R\$ 16.855,75); Vale Real (R\$ 19.000,14) e Pareci Novo (R\$ 19.953,09).

Tais informações caracterizam, brevemente, o espaço de ação das atividades de pesquisa e de extensão tecnológicas desenvolvidas pelo Projeto.

\section{O PERFIL SOCIECONÔMICO, O USO E A APROPRIAÇÃO DAS TICS PELA AGRICULTURA FAMILIAR DO VALE DO CAÍ-RS}

Nesta seção serão destacados os resultados da pesquisa e as atividades de extensão realizadas no âmbito do Projeto suprareferido. Foram entrevistadas 375 propriedades rurais e, das atividades de pesquisa, obtiveram-se os seguintes resultados:

Sobre o perfil socioeconômico dos agricultores entrevistados:

a) estado civil: a maior parte constitui-se de pessoas casadas (207), sendo 114 pessoas solteiras, 17 viúvos e 17 em união estável;

b) a idade média dos entrevistados é de 41,39 anos, tendo o mais idoso 83 anos;

c) arranjo familiar e condições de moradia: a maior parte dos entrevistados (340) reside com familiares na propriedade; em 17 propriedades reside apenas o casal; 12 respondentes evidenciaram que vivem com outras pessoas que não são da família; 5 informaram que moram sozinhos e um não identificou sua condição;

d) escolaridade: em geral, os produtores rurais apresentam baixa escolaridade, sendo que mais da metade $(52,8 \%)$ possui somente o Ensino Fundamental Incompleto, enquanto que apenas 15 iniciaram e 13 concluíram um curso superior;

e) a renda, entre as famílias analisadas, se situa na faixa de até três Salários Mínimos, o que corresponde a $71 \%$ das propriedades;

f) dentre as atividades desenvolvidas nas propriedades se destaca a silvicultura, apontada por 60 entrevistados como a primeira atividade a gerar renda para a propriedade. Outras atividades de destaque são a citricultura (48 propriedades), a criação de gado de leite (23 propriedades), a olericultura (20 propriedades), a 'agricultura' (sem maiores qualificações), apontada por 29 entrevistados e a avicultura (19 propriedades).

Sobre o uso e a apropriação das TICs: 
a) o número de bens de comunicação e de informática engloba a posse de telefone celular, microcomputador de mesa (desktop), notebook e tablet. Verifica-se que somente 16 propriedades não tem nenhum destes itens, ao passo que 21 propriedades $(5,6 \%)$ possuem os quatro tipos de equipamentos;

b) desagregando estas informações por combinações possíveis de posse temos a seguinte situação: com relação à posse de celular, apenas 19 entrevistados evidenciaram não o possuir. Do total de 375 entrevistados, 129 revelaram possuir computadores, 154 possuem notebook (uma propriedade tem 3) e 50 informaram possuir tablet. Como há a possibilidade de uma propriedade ter mais de um dos equipamentos perguntados, o cruzamento de respostas apresentou 58 propriedades possuem computador e notebook, enquanto que 16 propriedades não têm nem celular, nem computador, nem notebook e tablet. A combinação mais frequente é de celular e notebook, presente em 152 propriedades (ou 40,53\% das propriedades entrevistadas);

c) quanto à posse de cada equipamento em particular, das 375 propriedades entrevistadas, em 356 há telefone celular (94,93\%), 154 tem notebook, 129 tem computador de mesa (desktop) e 50 possuem tablet;

d) a frequência diária de uso de notebook/tablet/computador é corriqueira para pouco mais da terça parte das propriedades entrevistadas (apenas 33,6 \% das propriedades usam diariamente), enquanto que quase a metade não usa equipamentos de informática;

e) com relação ao acesso à internet, 46,1\% dos entrevistados acessam diariamente a rede, enquanto que $11,7 \%$ acessam pelo menos uma vez por semana. Porém, $42,1 \%$ ou não acessam ou não costumam utilizar a Internet, quadro que reflete a pouca acessibilidade na zona rural e/ou o pouco interesse em seu uso;

f) o acesso diário à internet mais frequente é de até uma hora diária (29,6\%), mas considerando que $37,9 \%$ não acessam a internet (142 propriedades) e que 150 propriedades não têm nem computador de mesa nem notebook, o uso e disseminação de conhecimentos e tecnologias pela rede mundial de acesso à informação representa um obstáculo a ser vencido na região;

g) as atividades preferidas quando do acesso à Internet foram identificadas genericamente como "pesquisas" (126 citações), seguidas pela busca por "notícias" (100 citações), "músicas e filmes" (78 citações), "jogos" (59 citações), "comunicações instantâneas" (58 citações) e "e-mail", com 55 citações. Como era solicitada a indicação de três atividades, a soma de respostas excede a 375 (total de propriedades entrevistadas).

As atividades de extensão realizadas foram:

a) oficina de integração com os agricultores sobre a utilização das principais tecnologias de informação e de comunicação, especialmente o uso da internet, e-mail, acesso a sites, comunicadores instantâneos e demais funcionalidades básicas existentes;

b) oficina de integração com palestra sobre a importância da educação financeira e do controle dos gastos;

c) construção de planilhas eletrônicas (Excel), de forma coletiva, com o objetivo de facilitar o processo de gestão da propriedade e dos custos de produção através do acesso às informações sobre o estabelecimento rural, do acompanhamento das principais variáveis econômicas e da evolução das propriedades, contribuindo, desta forma, para a tomada de decisão;

d) acompanhamento dos agricultores in loco visando ao monitoramento e o auxílio no registro das informações, processo realizado pelos bolsistas e integrantes do projeto;

e) realização de palestras sobre temas relacionados com as perspectivas de mercado, os custos de produção, a gestão financeira e contábil da propriedade rural. 
0 trabalho realizado pela equipe do Núcleo tem procurado avançar em termos de intervenção, no sentido de construção coletiva, ou seja, de aproximar os sistemas de sentido, de aproximar a Universidade à Comunidade, o conhecimento científico ao conhecimento popular. Esse encontro de mundos distintos é desafiador e será mais bem discutido na seção sobre gestão rural.

O Núcleo também realizou, participou e auxiliou os agricultores familiares em diversas atividades, dentre elas destacam-se:

a) participação na Audiência Pública Acesso à Telefonia Móvel e Internet - nesta oportunidade foi apresentado para o público presente o resultado da pesquisa que originou o Núcleo. Esses resultados foram encaminhados para a Assembleia Legislativa aos cuidados do Deputado Elton Weber para dar subsídios à construção do Projeto de Lei sobre Telefonia Móvel no Meio Rural;

b) auxílio para participação de dois agricultores vinculados ao Núcleo na Chamada Pública do Programa Nacional de Alimentação Escolar (PNAE) do Instituto Federal de Educação, Ciência e Tecnologia do Rio Grande do Sul - IFRS, campus de Feliz;

c) participação e acompanhamento dos agricultores no Seminário sobre Agroindústria realizado pelo SEBRAE;

d) participação no Seminário sobre a Produção Agroindustrial Artesanal realizado pela FETAG e UERGS e elaboração de documento que será enviado ao Ministério Público Estadual para discussão sobre a situação da agricultura familiar;

e) participação do Dia C da Ciência com a Oficina de Integração sobre Empreendedorismo, Cooperação e Motivação para o Trabalho conduzida por Carlos Esau;

f) participação em dois Programas de Rádio - Rádio América e Rádio Viva - para divulgação da palestra acima referida em alusão ao Dia $\mathrm{C}$ da Ciência.

Assim, constatou-se que o processo de intervenção realizado junto aos agricultores familiares através do projeto de extensão tecnológica possibilita a compreensão sobre a necessidade de se considerar as particularidades concretas de todos os agricultores, pois eles não podem ser analisados sob um mesmo patamar à medida que se identificam diferenças no que tange aos sistemas de sentido, de significados e, especialmente, com relação as suas condições objetivas de vida (AREND, DEPONTI e KIST , 2017).

\section{TECNOLOGIAS DE GESTÃO: A GESTÃO RURAL DA PROPRIEDADE REALIZADA PELOS AGRICULTORES FAMILIARES DO VALE DO CAÍ}

Neste item serão apresentados elementos empíricos identificados através das oficinas de integração referentes aos processos de gestão da propriedade rural dos agricultores familiares vinculados ao Núcleo. Destaca-se que se compreende por gestão rural não somente os aspectos vinculados ao controle contábil e gerencial, mas à propriedade como um todo, relacionando-se a aspectos econômicos, financeiros, administrativos, ambientais e sociais que qualificam a tomada de decisão. Dessa forma, a gestão contábil e gerencial engloba o controle de despesas e de receitas a partir de fluxo de caixa, a informações mais detalhadas sobre renda bruta, renda líquida, índices de eficiência econômica, custos de produção.

Embora o Núcleo tenha sido criado no ano de 2017, o trabalho junto aos agricultores familiares no Vale do Caí vem sendo realizado desde 2012 quando da realização de um Projeto Piloto, que consistiu em um levantamento com 10 famílias de agricultores familiares das atividades de pesquisa e de extensão tecnológica que foram realizadas no período de 2012 a 2014. 0 Piloto permitiu à equipe do projeto qualificar suas ações, buscando superar alguns obstáculos, aprofundar as parcerias e estreitar os vínculos com os agricultores familiares. Tal situação contribuiu para a qualificação de algumas atividades e também para a reflexão sobre algumas ações. 
Nesse sentido, salienta-se que os agricultores foram separados em dois grupos, um com aqueles que de fato possuíam interesse na gestão rural e no outro grupo os demais agricultores. Dessa forma, as oficinas de gestão rural foram realizadas para o grupo de agricultores que já possuía compreensão sobre sua importância e que manifestava tal interesse. Para os demais agricultores foram realizadas atividades de acordo com suas demandas, privilegiando outras temáticas. Esta ação buscou aproximar os objetivos do projeto aos objetivos dos agricultores, o que possibilitou um processo de construção coletiva da aprendizagem e do conhecimento.

Em função desse processo de reflexão sobre as ações desenvolvidas pela equipe do Núcleo foram inseridas algumas mudanças na condução do processo de acompanhamento dos agricultores em suas propriedades e da introdução dos controles econômicos e financeiros. Primeiramente foi distribuído um caderno de controle de despesas e de receitas e uma cartilha para levantamento patrimonial. No entanto, o preenchimento das informações, na maioria dos casos, foi realizado em conjunto com a equipe. Posteriormente, a equipe reuniu-se e analisou cada uma das propriedades realizando os cálculos contábeis e fazendo um diagnóstico para cada propriedade. Este diagnóstico será repassado aos agricultores e será discutido em família. Após, os agricultores interessados poderão participar de oficinas de integração que serão realizadas com o objetivo de discutir e de aprofundar o uso de controles contábeis e econômicos e o levantamento dos custos de produção. Essas oficinas estão agendadas para o ano de 2018.

A construção de processo de gestão rural que possa ser apropriado pelos agricultores familiares está sendo o desafio da equipe neste momento. Conforme já mencionado por Deponti $(2014$, p. 11) há "descompasso entre inúmeros softwares e ferramentas de gestão e o baixo uso por parte dos agricultores, aliado à desconexão das ferramentas existentes com a capacidade e a necessidade dos agricultores".

Em função dessa situação a equipe do projeto desafiou-se a construir coletivamente alternativas de gestão e de controle mais apropriados pelos agricultores, uma vez que tais registros foram acompanhados pela visita in loco às propriedades pelos bolsistas e pesquisadores. No entanto, embora esta estratégia pareça a mais acertada e consoante com a literatura no que se refere ao desenvolvimento do sentimento de pertencimento e de valorização do "saber fazer" dos agricultores, na prática destaca-se que situação descrita exige a maturação de um processo de mediação social que "não se assemelha aos objetivos das políticas públicas e dos projetos de pesquisa e de extensão financiados pelas diversas organizações que apresentam prazo definido, objetivos específicos, resultados esperados, metas alcançadas" (DEPONTI; KIST; AREND, 2017, p. 12). Além desta constatação, também se destaca que, no Vale do Caí, de acordo com a pesquisa de Arend, Deponti e Kist (2017), $49,1 \%$ os agricultores familiares apresentam ensino fundamental incompleto, fato que dificulta a utilização dos controles gerenciais e contábeis, considerando a complexidade de um processo de gestão de custos de produção no meio rural.

Sobre essa questão, o Núcleo questiona-se sobre a homogeneidade dos processos de controle econômico, pois se acredita que há uma heterogeneidade de possibilidades no rural, um mosaico de práticas, há especificidades no processo produtivo, na formação da família, na escolha dos cultivos. Salienta-se que nem todas as propriedades necessitam de complexos controles gerenciais e contábeis. A grande dificuldade está em compreender cada caso quando se trata de gestão rural para a agricultura familiar.

No entanto, embora a equipe tenha realizado uma proposta de construção coletiva do conhecimento e dos instrumentos de controle gerencial, observou-se que há grande dificuldade na prática de concretização dessa proposta, pois há obstáculos no que se refere à reunião de toda a equipe de trabalho, à participação dos agricultores, à aproximação entre dos distintos conhecimentos, à motivação para continuidade do processo pelos agricultores de forma autônoma.

\section{CONSIDERAÇÕES FINAIS}

Verifica-se que ainda há muitos desafios com relação às atividades de pesquisa e de extensão tecnológicas propostas através do projeto referido, pois se reconhece que algumas delas ainda apresentam um distanciamento entre a práxis e o cotidiano dos agricultores. Nesse sentido, torna-se fundamental a identificação 
desta realidade para que se possa, através da pesquisa, compreender a realidade concreta de forma a qualificar os processos interventivos através das atividades de extensão.

Dessa forma, a equipe do projeto desafiou-se a construir coletivamente alternativas de gestão e de controle mais apropriados pelos agricultores, uma vez que tais registros foram acompanhados pela visita in loco às propriedades pelos bolsistas e pesquisadores.

Os resultados desta atividade ainda não são conclusivos, pois este processo ainda está em execução, mas observa-se que esta estratégia se apresentou mais efetiva no que se refere ao desenvolvimento do sentimento de pertencimento e de valorização do "saber fazer" dos agricultores.

No entanto, destaca-se que situação descrita exige um horizonte de longo prazo, de maturação e de entrosamento da equipe com os demais participantes, de recursos financeiros, de paciência quanto aos resultados, pois o processo avança e retrocede a todo o momento. Estas características não se assemelham aos objetivos das políticas públicas e dos projetos de pesquisa e de extensão financiados pelas diversas organizações que apresentam prazo definido, objetivos específicos, resultados esperados, metas alcançadas.

Várias foram as dificuldades encontradas no tocante aos processos de gestão da propriedade pela agricultura familiar, pois o Projeto confirmou a indicação da literatura de que não há uma cultura de registro de informações por parte dos agricultores, associada à inadequação das ferramentas existentes, de difícil compreensão devido ao baixo grau de instrução dos sujeitos envolvidos e da complexidade do processo de gestão da propriedade rural.

Assim, concluiu-se que o referido Núcleo possibilita a articulação entre o ensino, a pesquisa e a extensão e o envolvimento dos alunos, dos professores da graduação da pós-graduação, da comunidade regional, das organizações sociais como o Sindicato de Trabalhadores Rurais, a EMATER/RS-ASCAR, a ACl Montenegro e Pareci Novo.

Por fim, os resultados apresentados confirmam que a produção do conhecimento somente é possibilitada através da articulação entre o conhecimento científico dos professores, dos alunos e dos parceiros envolvidos no processo, em conjunto com o conhecimento dos próprios agricultores, adquiridos ao longo de suas trajetórias de vida, resultando assim na construção de um conhecimento híbrido que é obtido através da interface social. Assim, concluiu-se que o referido Núcleo possui uma relevância social na medida em que possibilita através da articulação entre o ensino, a pesquisa e a extensão, a produção do conhecimento e a contribuição para o desenvolvimento regional.

\section{REFERÊNCIAS}

AREND, S. C.; DEPONTI, C. M.; KIST, R. B. B. O uso de TIC pela agricultura familiar no território do Citros: Vale do Caí-RS. Informe Gepec (Impresso), v. 20, p. 71-84, 2016. Disponível em: http://e-

revista.unioeste.br/index.php/gepec/article/view/15638. Acesso em 16 de março de 2018.

BALBONI, M. R. Por detrás da inclusão digital: uma reflexão sobre o consumo e a produção de informação em centros públicos de acesso à Internet no Brasil. 2007. 210 f. Tese (Doutorado em Ciências da Comunicação) - Escola de Comunicação e artes, Universidade de São Paulo, São Paulo, 2007.

BATALHA, M. O; BUAINAIN, A. M.; SOUZA FILHO, H. M. Tecnologia de gestão e agricultura familiar. In: SOUZA FILHO, H. M.; BATALHA, M. O. Gestão integrada da agricultura familiar. São Paulo: edUFSCar, 2004, p. 43-65.

BARCELOS, L. et al. Agricultura familiar e tecnologias de informação e comunicação (tics): projeto piloto Vale do Caí. Revista Jovens Pesquisadores, Santa Cruz do Sul, v. 4, n. 1, p. 106 - 117, 2014. Disponível em:

<https://online.unisc.br/seer/index.php/jovenspesquisadores/article/view/4454>. Acesso em: 6 de junho 2017.

BUAINAIN, A. M.; FONSECA, R. B. Agricultura familiar no Brasil: a visão acadêmica. In: Agrópolis. Cosecha Fina/Zafra de Verano. Campo Acadêmico Brasil. Universidade Campinas, 2011. p. 108 -113.

CETIC. Pesquisa sobre o uso das tecnologias de informação e comunicação nos domicílios brasileiros [livro eletrônico]: TIC domicílios 2015. São Paulo: Comitê Gestor da Internet no Brasil, 2016. Disponível em: http://cetic.br/pesquisa/domicilios/. Acesso em 16 de março de 2018.

CABRERA, L. C.; SILVEIRA, A, C, M,; SILVEIRA, V. C. P. Tecnologias de informação e comunicação: o caso do Sistema de Alerta. In: $48^{\circ}$ Congresso da Sociedade Brasileira de Economia e Sociologia Rural, 48., 2010, Campo Grande. Anais eletrônicos ... Campo Grande: Sociedade Brasileira de Economia e Sociologia Rural, 2010. 1 CD-ROM. 
CENTRO DE ESTUDOS SOBRE AS TECNOLOGIAS DA INFORMAÇÃO E DA COMUNICAÇÃO (CETIC). Pesquisa sobre o uso das tecnologias de informação e comunicação nos domicílios brasileiros [livro eletrônico]: TIC domicílios 2015. São Paulo: Comitê Gestor da Internet no Brasil, 2016. Disponível em: <http://cetic.br/pesquisa/domicilios/>. Acesso em 06 de junho 2017. DEPONTI, C. M. As "agruras" da gestão da propriedade rural pela agricultura familiar. REDES, Revista do Desenvolvimento Regional, Santa Cruz do Sul, v. 19, ed. especial, 2014, p. 9-24. Disponivel em: https://online.unisc.br/seer/index.php/redes/article/download/5150/3555. Acesso em 16 de março de 2018.

DEPONTI, C. M. Intervenção para o desenvolvimento rural: o caso da extensão rural pública do Rio Grande do Sul. Porto Alegre, 2010. 276 f. Doutorado (Desenvolvimento Rural) - Universidade Federal do Rio Grande do Sul, Porto Alegre, 2010. Disponível em: http://hdl.handle.net/10183/35398. Acesso em 16 de março de 2018.

DEPONTI, C. M.; KIST, R.B.B.; AREND, S. Desenvolvimento regional e agricultura familiar: o uso e a apropriação das Tics no Vale do Caí - RS, Desenvolvimento Regional em debate, v. 5, n. 2, p. 170-187, jul./dez. 2015. Disponível em: https://dialnet.unirioja.es/descarga/articulo/5443888.pdf. Acesso em 16 de março de 2018.

DEPONTI, C. M.; KIST, R. B. B.; AREND, S. C.; TIC e Agricultura Familiar: uma experiência de pesquisa e de extensão tecnológica no território do Citros-RS. In: Anais Seminário Internacional de Desenvolvimento Regional, p., 2017. Disponível em: http://online.unisc.br/acadnet/anais/index.php/sidr/article/view/16413. Acesso em 16 de março de 2018.

DEPONTI, C. M., KIST, R. B. B., MACHADO, A. As Inter-relações entre as Tic e a Agricultura Familiar. Revista Eletrônica Competências Digitais para a Agricultura Familiar. RECODAF. V.03, $n^{\circ}$. 01. 2017. p. 4-23. Disponível em: http://codaf.tupa.unesp.br:8082/index.php/recodaf/article/view/47. . Acesso em 16 de março de 2018.

DEPONTI, C. M., FELIPPI, A. C. T., DORNELLES, M. Os usos e as apropriações das Tics na agricultura familiar em regiões do sul do Brasil. Anais do VII Seminário Internacional sobre Desenvolvimento Regional. Globalização em Tempos de Regionalização - Repercussões no Território, Santa Cruz do Sul, RS, Brasil, 2015.

DEPONTI, C. M. et al. Desenvolvimento regional e ações no território: o uso e a apropriação de tecnologias e informação e de comunicação no Vale do Caí-RS. In: CONGRESSO INTERNACIONAL SETED-ANTE, 2., 2015, Santiago de Compostela. Anais... Santiago de Compostela, 2015. p. 991-1006.

Tecnologias de informação e de comunicação (TICs) e agricultura familiar - a incompatibilidade entre a existência e a apropriação: Projeto Piloto de Montenegro-RS. In: CONGRESSO Da SOBER, 53., 2015, Paraíba. Anais... Paraíba, 2015.

DEPONTI, C. M.; ENGEL, V.; AREND, S. C.O uso de tecnologias de informação e de comunicação (TICs) pela agricultura familiar no Vale do Caí: Projeto Piloto de Montenegro-RS. In: BIENAL DEL COLOQUIO DE TRANSFORMACIONES TERRITORIALES, 10., 2014, Córdoba. Anais..., Córdoba, 2014.

ECKHARDT, M.; LEMOS, A. C. F. V. 0 impacto da tecnologia da informação e comunicação. Sociais e Humanas, Santa Maria, v. 20, set. 2007, p. 295-312. Edição Especial

FEE (Fundação de Economia e Estatística) - Corede Vale do Caí. Rio Grande do Sul: 2010. Disponível em:

https://www.fee.rs.gov.br , Perfil Socioeconômico , COREDES. Acesso em: 14 de mai. de 2015.

FELIPPI, A. T., DEPONTI, C. M, DORNELES, M. TICs na agricultura familiar: os usos e as apropriações em Regiões do Sul do Brasil. Revista Brasileira de Gestão e Desenvolvimento Regional. Taubaté, v. 13, n. 1, p. 3-31, jan./abr. 2017. Disponível em: http://www.rbgdr.net/revista/index.php/rbgdr/article/view/2727/569. Acesso em 16 de março 2018.

LEADER. Cadernos do Observatório. As tecnologias de informação a serviço do desenvolvimento rural. №4, 2000.52 p.

LÜBECK, E. A exclusão digital e a apropriação da internet no contexto rural brasileiro. 2004. Dissertação (Mestrado) Universidade Federal de Santa Maria, Santa Maria, 2004.

MARION, J. C.; SEGATTI, S. Sistema de gestão de custos nas pequenas propriedades leiteiras. In: MARION, J. C.; SEGATTI, S. Custos e @gronegócio on line, v. 2, n. 2, jul./dez. 2006. Disponível em: <www.custoseagronegocioonline.com.br>. Acesso em: 10 abr. 2014.

MILLARD, J. et al. As tecnologias da informação ao serviço do desenvolvimento rural. Tradução de Andréia Roma. 4. ed. São Paulo: Leader, 2000.

PACIEVITH, P. Tecnologias de informação e comunicação. 2014. Disponível em:

<http://www.infoescola.com/informatica/tecnologia-da-informacao-e-comunicacao>. Acesso em: 6 jun. 2017.

SORJ, B. Brasil@povo.com: a luta contra a desigualdade na Sociedade da Informação. Rio de Janeiro: Jorge Zahar Ed., 2003. SOUZA, J.; BINKOSWKI, P. As Transformações Dos Sistemas Agrários No Vale Do Caí, Rio Grande Do Sul, Porto Alegre. 2007 , $15 \mathrm{p}$.

THORNTON, R. (Ed.). A extensão rural em debate - concepções, retrospectivas, mudanças e estratégias para o Mercosul. Buenos Aires: INTA, 2003.

VIEIRO, V. e SILVEIRA, A. M. Apropriação de tecnologias de informação e tecnologias de informação no meio rural brasileiro. Cadernos de Ciência \& Tecnologia, Brasília, v. 28, n. 1, p. 2 57-277, jan./abr. 2011. Disponível em:

https://www.marilia.unesp.br/Home/.../apropriacao-de-tic-no-meio-rural-brasileiro.pdf. Acesso em 16 de março de 2018. VIERO, V. C. Comunicação rural on-line: o modelo de monitoramento agrícola do Sistema Irriga da Universidade Federal de Santa Maria. Monografia (Graduação). Santa Maria: UFSM, 2007.

VIERO, V; SOUZA, R. Comunicação rural on line: promessa de um mundo sem fronteiras - estudo de caso do modelo de monitoramento agrícola do Sistema Irriga da Universidade Federal de Santa Maria. CONGRESSO SOBER, 46., 2008. Rio Branco. Anais... Rio Branco:

WAISELFISZ, J. J. Mapa das desigualdades digitais no Brasil: rede de informação tecnológica Latino Americana (RITLA). Brasília: Instituto Sangari, 2007. 